\title{
Situation of Artificial Depigmentation among Women in 2016 to Bobo-Dioulasso, Burkina Faso
}

\author{
Jean-Baptiste Andonaba', Nina Nessiné Korsaga-Somé2, Boukary Diallo ${ }^{1}$, Etienne Yabré1, \\ Issouf Konaté ${ }^{1}$, Amina Nomtondo Ouédraogo², Pascal Niamba², Adama Traoré2
}

${ }^{1}$ INSSA, Université Nazi Boni de Bobo-Dioulasso, Bobo-Dioulasso, Burkina Faso

${ }^{2}$ UFR/SDS, Université Ki-Zerbo de Ouagadougou, Ouagadougou, Burkina Faso

Email: jb_andonaba@yahoo.fr

How to cite this paper: Andonaba, J.-B., Korsaga-Somé, N.N., Diallo, B., Yabré, E., Konaté, I., Ouédraogo, A.N., Niamba, P. and Traoré, A. (2017) Situation of Artificial Depigmentation among Women in 2016 to Bobo-Dioulasso, Burkina Faso. Journal of Cosmetics, Dermatological Sciences and Applications, 7, 189-198.

https://doi.org/10.4236/jcdsa.2017.72017

Received: May 25, 2017

Accepted: June 24, 2017

Published: June 27, 2017

Copyright $\odot 2017$ by authors and Scientific Research Publishing Inc. This work is licensed under the Creative Commons Attribution International License (CC BY 4.0).

http://creativecommons.org/licenses/by/4.0/

\begin{abstract}
INTRODUCTION: The artificial depigmentation (DA) is a practice that aims to reduce the natural pigmentation of the skin by the use of depigmenting products (DP). In Burkina Faso, few studies have been made on the issue and the last date of 2003. The objective of the study is to realize an overview of the DA phenomenon in women population in Bobo-Dioulasso City. METHODS: This is a descriptive cross-sectional study held from April 16th to April 30th 2016 including 437 women aged from 13 to 55 years old. A multi-stage random sampling was realized A chi-square test was used to compare groups with significant threshold of 5\%. RESULTS: The prevalence of the use of DP $(67.28 \%$ with IC95 $=[63.52-71.03])$. The mean age of users was 27.5 years old; the typical profile was women from 30 to 35 years old (85.7\%), with elementary study level, (73.47\%), housewife's (75.19\%) and monogamous (71.98\%). the products used was those made of hydroquinone (81.6\%), EDTA (8.33\%), kojic acid (4.86\%), mixtures (11.12\%) or unknown products $(14.58 \%)$. The origin of the product was doubtful for almost all the cases (98.96\%). The monthly mean cost of this practice for a single user is 1710 CFA. Complications were reported in $62.5 \%$ of users, and the most found was dyschromia (85.87\%), acne (17.39\%) and burns (10.32\%). DISCUSSION: The DA is in great progress in Bobo-Dioulasso (2 out of 3 women) compared to half, thirteen years ago. The hydroquinone was markedly the most frequent DP while there was an apparent lack of corticosteroids and mercuries replaced by the new depigmenting agent such as EDTA and kojic acid. This result contrasted with the classic combination hydroquinone-dermocorticoïd-mercuries reported by previous studies. CONCLUSION: The low-cost of DP could explain the magnitude of the artificial depigmentation phenomenon. Other studies should be conducted in order to establish with precision the composition
\end{abstract}


of these products and their causality in the occurrence of common complications. Research in cosmetology should make it possible to provide women with safe products that respect their deep needs.

\section{Keywords}

Artificial Depigmentation, Products, Women, Bobo-Dioulasso

\section{Introduction}

Artificial depigmentation (DA) also named self-willed depigmentation or cosmetic depigmentation or color mimesis, can be defined as a social practice aimed to reduce the natural pigmentation of the skin by the use of depigmenting agents [1] [2]. A long time in the past, for esthetic purposes, human used various agents such as soap, milk, butter, plants, cosmetic agents and pharmaceutical products [3]. In the esthetic univers, a practice distinguishes itself: the cosmetic skin depigmentation. Many studies related to this practice have been conducted throughout the word [2] [4]. These studies emphasized that mostly sub-Saharan African women are involved in this phenomenon [4]. This practice also includes men from some regions especially the central Africa. Additionally, women from other part of the world such as Mayot, the Maghreb, Saoudi Arabia, India and Pacific Asia are also involved [2]. Many studies have been conducted in WestAfrica about this topic. This practice is common in many countries leading to its specific designation depending of the country: "xeesal" or "leeral" in Senegal, "tchatcho" in Mali and in Burkina Faso, "boju" in Benin [1] [2]. In Burkina Faso, some pionneer studies were conducted. In 1998, Djabaku [5] in a study held in Ouagadougou found a prevalence of $21.89 \%$. Another study conducted in 2003 by Traoré [1] reported prevalence of $39.5 \%$ in Ouagadougou and $49.2 \%$ in Bobo-Dioulasso, respectively.

What is the situation now, 10 years later in Burkina Faso? Is the trend increasing or decreasing? Did the products used, the complications associated and the motivations have changed? All these questions lead us to assess the current situation of artificial depigmentation in women population in Bobo-Dioulasso.

\section{Methods}

We conducted a one-step descriptive cross-sectional study from April 16th to April 30 2016. Data were collected with a questionnaire. Type Negroid women aged from 13 to 55 years old during the study period and have been living in Bobo-Dioulasso for more than 6 months were included in the study. The sample size calculation was based on a prevalence of 50\% [6] land a precision $\alpha=5 \%$ giving 384 women to interview. We added $10 \%$ of the sample size (39 women) for non-responders giving a total of 423 women. A total of 437 women meeting the inclusion criteria were interviewed in Bobo-Dioulasso city. Our study was held in all three boroughs. The sample size per borough was estimated according 
to the size of the population of this borough. The number of women included per sector was obtained by dividing the number of women per borough by the total number of sectors that should be visited. In each sector, data collectors went in the center of the area and then use the "bottle method": the street, the direction, and the side of the street were randomly chosen. Then, field workers visited each third house. Socio-demographic, cosmetic, clinical and psychological variables were studies. Were considered as depigmenting agents, product that the composition were known and that a least one component has a confirmed depigmenting activity, product with unknown composition but on which was mentioned the depigmenting effect, products with unknown composition, that can be found with retailers and are known for their depigmenting activities according to many sources interviewed during the pre-study. Was defined as woman user of depigmenting agent, any woman who is currently using or who had used a depigmenting product (DP). A questionnaire was elaborated for the data collection. Data was collected through a face to face interview then data of a clinical examination are then reported on the questionnaire. Data was entered with the software EPI-INFO 7 database. Data analysis was performed with Chisquare test used to compare groups of depigmenting agents' users.

\section{Results}

Among a total of 437 women included in the study, 294 were using a DP giving a prevalence of $67.28 \%(95 \mathrm{IC}=[63.52-71.03])$. The mean age of users was 27.5 years with a standard deviation (Std) of 8.93. Women under 30 years old represented $63.26 \%$ of the sample (186/294). The age group $30-35$ years was the most represented with $85.71 \%$ (54/63) (Figure 1). Most of the users were literate (Elementary, middle school, high school and not formal education) with $71.42 \%$ $(n=210)$. Among literate, the prevalence was higher in users who level of education was elementary school with $73.47 \%(n=72)$, followed by women with no formal education with $71.43 \%(n=15)$. However, an in-depth analysis highlighted

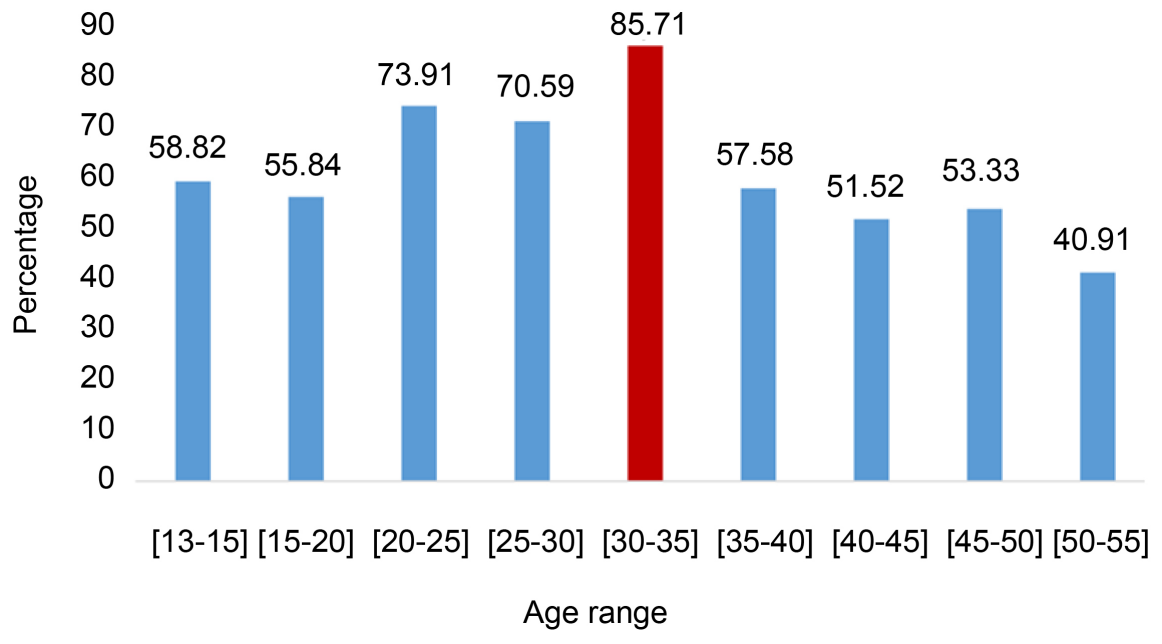

Figure 1. Distribution of depigmenting products users by age. The red bar corresponding to the most represented age group. 
that women with a higher education (College and graduate schools or university) were using the most DP (Table 1$)(p=0.0002)$. The professional category the most active in using DP with a prevalence of $75.19 \%(n=100)$ is housewives $(p=$ 0.019 ) (Table 2). Then followed the category of retailers shopping with $73.6 \%$ $(n=92)$ and workers public/private with $61.4 \%(n=21)$. Users frequency repartition according to the matrimonial status, showed a prevalence of DP use of $71.98 \%(n=131)$ in monogamous women, $70.45 \%(n=31)$ in polygamous and $63.64 \%$ in single women $(n=126)$. Married women depigmented more than single women $(p=0.04)$ (Table 3$)$. Products including hydroquinolone as active substance was the most used with $81.60 \%$ (Figure 2). Among 294 users, 153

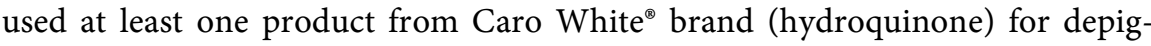
mentation giving a frequency of $52.08 \%$ (Figure 3). Only 1.04\% (3/294) of users was buying their products in a pharmacy compare to $98.96 \%(291 / 294)$ in the stores, markets and street vendors. The mean monthly cost of products for one user is $1710.07 \mathrm{CFA}$, with the highest cost of $7000 \mathrm{CFA}$ and the lowest of 900 CFA. The use of DP led to dermatological complications in most cases. The overall prevalence of dermatological complications in women users was $62.50 \%$ (184/294). The most frequent complications were dyschromias with $85.87 \%$ (158/184). These included hyperchromias, hypochromias, or both. Then, acne was the second most frequent complication with $17.39 \%(32 / 184)$ and burns

Table 1. Correlation between depigmentation product users and their educational lever.

\begin{tabular}{ccccc}
\hline & Users & Non users & Total & P \\
\hline Literate & $210(67.6 \%)$ & $102(32.69 \%)$ & 312 & 0.98 \\
Illiterate & $84(67.2 \%)$ & $41(32.8 \%)$ & 125 & \\
Higher education* & $14(40 \%)$ & $21(60 \%)$ & 35 & 0.002 \\
Other* & $196(70.76 \%)$ & $81(29.24 \%)$ & 277 & \\
\hline
\end{tabular}

Higher education*: College and graduate school or University. Other ${ }^{\star}$ : Not formal education, middle school and high school levels.

Table 2. Correlation between depigmentation product users and their profession.

\begin{tabular}{ccccc}
\hline & Users & Non users & Total & P-value \\
\hline Retailer & $92(73.6 \%)$ & $33(26.4 \%)$ & 125 & 0.07 \\
Not retailer & $202(64.74 \%)$ & $110(35.26 \%)$ & 312 & 0.019 \\
Housewife & $100(80 \%)$ & $33(26.4 \%)$ & 125 & 312 \\
Not housewife & $192(62.18 \%)$ & $110(35.26 \%)$ & & \\
\hline
\end{tabular}

Table 3. Correlation between depigmentation product users and their matrimonial status.

\begin{tabular}{ccccc}
\hline & Users & Non users & Total & P \\
\hline Maried & 162 & 64 & 226 & $\mathbf{0 . 0 4}$ \\
Not maried & 132 & 79 & 211 & \\
Monogamous & 131 & 51 & 182 & 0.84 \\
Polygamous & 31 & 13 & 44 & \\
\hline
\end{tabular}




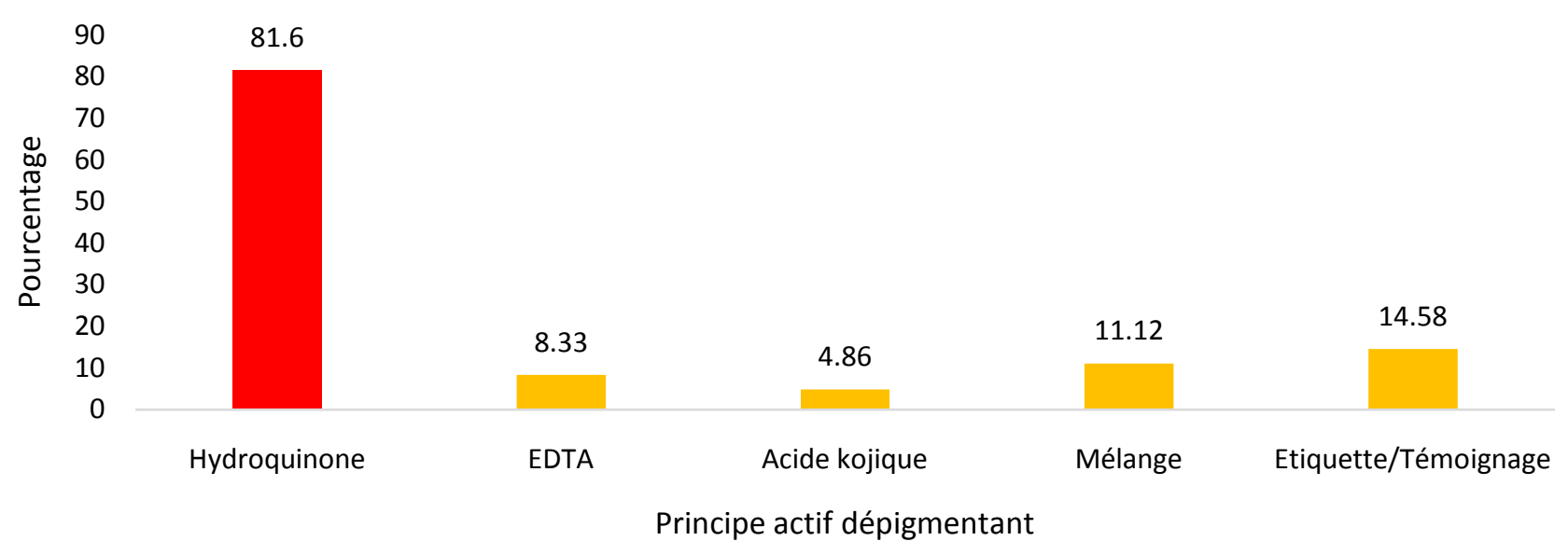

Figure 2. Frequency reparation of users according to the active substance responsible of the depigmentation. N.B.: the total of the frequencies is greater than $100 \%$ because some women use simultaneously many depigmenting products including different active substances.

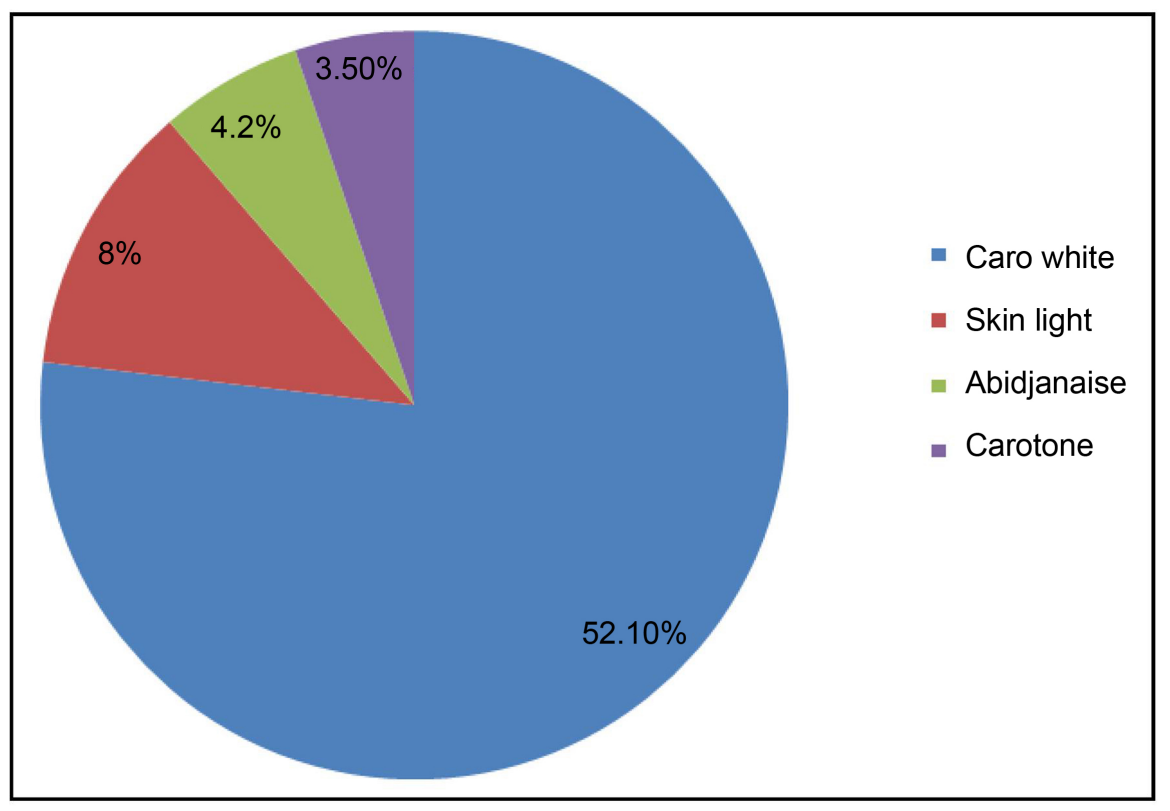

Figure 3. Distribution of depigmenting products users according to the trade name (the blue part being the more frequent).

were following with 10.32\% (19/184) (Table 4) (Figure 4 and Figure 5). Among 184 women with complications, only $9(4.89 \%)$ attended a healthcare facility. Through all these distresses (hard situations), women are looking for "ideal skin color": the brown was the best "ideal skin color" for women with 68.71\% (193/ 294). The "bright skin color" was the second desired skin color by women with $16.67 \%$. The other color desired was: without preference $(n=20)$, black $(n=14)$, yellow $(n=6)$, white $(n=3)$.

\section{Discussion}

Our study has some limitations. The chemical composition of products has not been determined in the laboratory for scientific confirmation. Therefore, we are 
Table 4. Frequency reparation of users according to the dermatological complications.

\begin{tabular}{ccc}
\hline Dermatological complications & Number & Frequency (\%) \\
\hline Dyschromias & 158 & 85.87 \\
Acne & 32 & 17.39 \\
Burns & 19 & 10.32 \\
Folliculitis & 16 & 8.88 \\
Stretch mark & 11 & 6.10 \\
Ochronosis & 2 & 1.10 \\
Lichen & 2 & 1.10 \\
Dermatophyta & 1 & 0.56 \\
Other & 6 & 3.19 \\
\hline
\end{tabular}

${ }^{*}$ other. hirsutism $(n=3)$, fine lines $(n=2)$, telangiectasia $(n=1)$. N.B. The total of percentage is greater than $100 \%$ because some users presented at leat 2 complications.

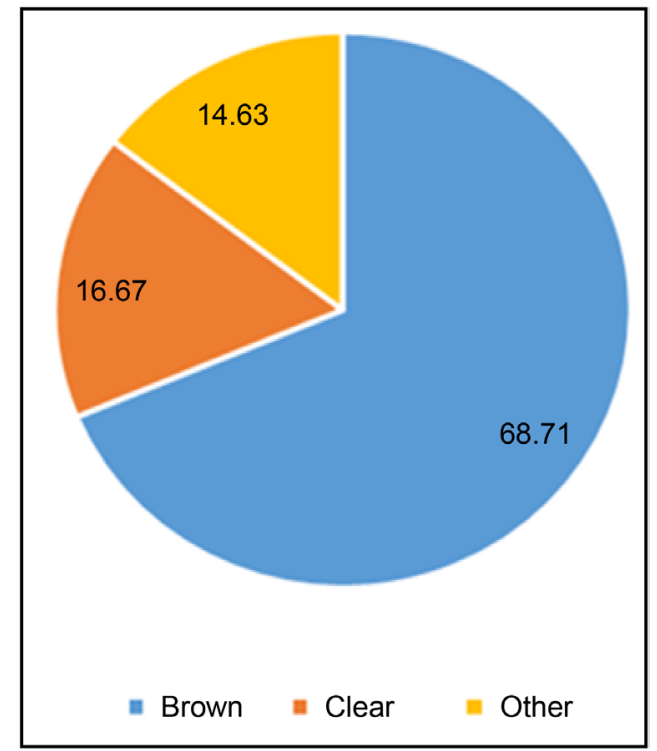

Figure 4. Distribution of depigmenting products users (expressed as percentages) according to the desired ideal complexion. ${ }^{\star}$ Other: without preference $(n=20)$, black $(n=14)$, yellow $(n=6)$, white $(n=3)$.
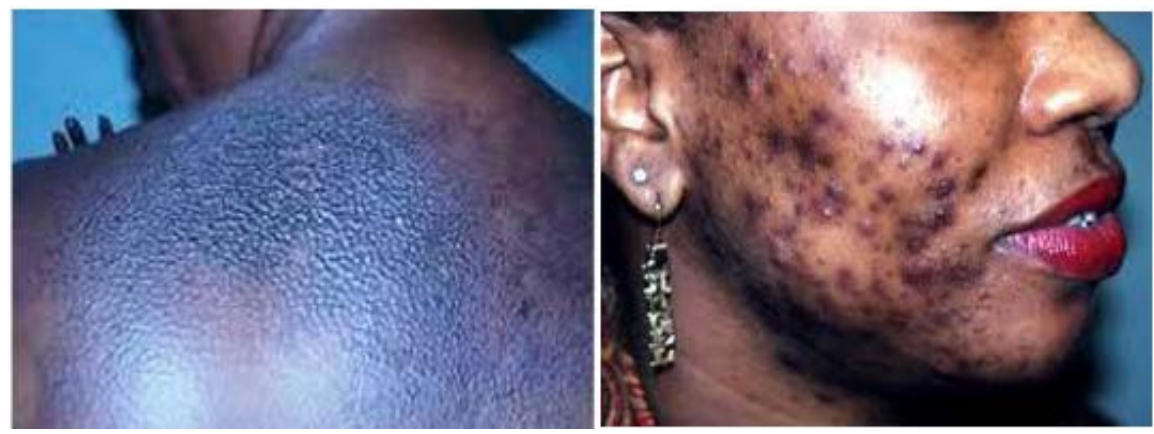

Figure 5. Complications with exogenous ochronosis of back at the left side and acne at the right one in two patients. 
cautious about the composition of some cosmetics. In fact, a study realized in 1995 in Dakar about a sample of 12 products reported a discrepancy between the actual compositions of the products compare to that were on the products labels [7]. The definition criteria of depigmentation led to the non-inclusion of some products which were considered as unclassified. However, the results of this study allow us to evaluate the growth of the phenomena in women population in Bobo-Dioulasso. Our study reported a prevalence of the use of DP of $67.28 \%$. This prevalence markedly increased by 18 points compare to the latest study conducted by Traoré et al. in Bobo-Dioulasso in 2003 that reported a prevalence of $49.2 \%$ in the general population in the same city [1]. This result could be explained by the fancy, the low cost of DP, the growth of communication means as well as the inefficacy of legal measures especially the law adopted in 2006 forbidding the publicity relative to DP [8]. This result is similar to the one of Wone et al. [9] that estimated in 1999 in Dakar (Senegal) a prevalence of 67\% in general population. Our prevalence is higher than the one of Pitché [10] in 1998 in Lomé (Togo) with 59\% and the one of Mahé [11] in 1993 in Bamako (Mali) with 25\%. The difference highlighted may be due to the interval of time between the other studies and ours. The users were mainly young people, as highlighted by the mean age of 27.5 years, the high representation of women less than 30 years old with $63.26 \%$ and the highest prevalence in the age group of 30 to 35 years old (85.71). This result corroborated the one of Traoré et al. in Burkina Faso [1] with a mean of 25.5 years, the group of less than 30 years was representing $75.8 \%$ and the one of Pitché et al. [10] in Lomé which showed that the DP use was most frequent in women less than 40 years. This result can be explain by the fact that the population of Burkina Faso is young, especially women with 71.36 old women less than 30 years old the census of 2006 [6]. We found a prevalence of $58.82 \%$ in the age group of 13 - 15 years, which is high. DP are used in a precocity manner and may be used by children under 13 years. This result suggest a longer time of percutaneous absorption of DP. The vast majority of users were literates. They were significantly using more DP than illiterates $(p=0.008)$. Our result was similar to the one of Traoré et al. [1] in Burkina Faso, of Pitché et al. [10] in Togo and of Mahé [11] in Mali who found significant difference between literate and illiterate with a higher usage in literate group. This difference may be explained by the easier way for literate to get the information through media [1]. However, this hypothesis may not be correct, because during our pre-survey we found that the information from one person to another one was the preferred channel of information. Nevertheless, in our sample, the group of women with high level of education was using less (40\%) DP. This may be due to the better knowledge about risks related of the use of depigmentation products. Housewives and retailers were the higher users of DP with $75.19 \%$ and $73.6 \%$. A similar result has been found by Djabaku in Ouagadougou (Burkina Faso), in 1998. For the retailer, it easy to understand that they have incomes allowing them to get regularly the products; however it's hard to understand how housewives are the highest group of users. This may be possible because of the low price of the 
products: 1 to 2 euros according to Ly in Sénégal [4], tube of dermocorticoïd starting at 500 CFA according to Del Giudice et al. [12], pot of ointment Caro White (hydroquinone) at around 1000 CFA according to our study. In our cultural context the housewives often have small jobs (retail, washing clothes, cleaning houses etc.) giving them incomes. Hydroquinone was the depigmenting active substance the most used. It was in the composition of the products of $81.60 \%$ of users. Then follow EDTA (8.33\%) and kojic acid (4.86\%). This result contrasted with the classic combination hydroquinone-dermocorticosteroidsmercuries reported by previous studies [4] [11] [12]. The lack of corticosteroids and mercuries on the products' labels may be due to the adaptation of cosmetics producers. In fact corticosteroids have a bad reputation [12] which may condemn them as cosmetics. The use of mercuries was very low according to Traoré et al. [1] who found a prevalence of $1.6 \%$. Besides that the increase use of new depigmenting agents was reported by the same authors as above, with products including kojic acid which was ranked third (12.5\%), then hydroquinone (33.1\%) and corticosteroids (26.6\%). Pitché [10] found that mixture products were often used as well as products with unknown composition. Caro White ${ }^{\varpi}$ (hydroquinone) was the brand of the DP the most used with more than $50 \%$ of users. The users mostly get their DP in cosmetic stores (54.51\%) throughout the city. However Traoré [1] in Burkina Faso reported that the vast majority (87.2\%) of users were buying their products in the mall. This report may be the consequence of the decentralization of DP stores making easy the geographical access to client. The monthly mean cost is about 1700 CFA per month in Bobo-Dioulasso. This cost is lower than the cost reported by Del Giudice [12] in Senegal who found a cost of 3000 XOF per month in 2003 in Dakar. Our result may be due to the reduction of the price of the DP over the time and to the economic level between the two countries. It is known that depigmentation is not costly now leading to the accessibility of DP by all the classes, and as result the rapid expansion of the phenomenon. We found complications in most women using DP (62.50\%). The most frequent complications were dyschromias (53.82\%) including most often hyperchromias (25.35\%). Then, follow acne (10.76\%) and burns (6.6\%). These results are closed to the findings of Traoré et al. (55.5\%) [1] and of Pitché et al. (69.2\%) [10]. The later authors also reported dyschromias, acne, as most frequent complications but atrophy was the third most frequent. The high frequency of burns in our study may be explained by the important exposure to the sun since our study was conduct during the dry season. Complications such as folliculitis, stretch marks, dermatophytia or hirsutism suggest the presence of corticosteroids in the products used by women. In fact, these complications are somehow specific to the pharmacological class including corticoid, therefore the hypothesis that corticoids are one component of DP identified in our study. We can suggest that they were included in the product with no mention on the label or they were in the products with no label. Only few users (9 out of 294) had dermatological treatment for cutaneous complications. Traoré [1] did similar observation with 5 consultations out of 248 users of DP. First, this 
attitude may be the result of the lack of information about the availability of dermatological care in Bobo-Dioulasso. In addition, the fear of the stigmatization by healthcare workers (bad judgments and moralizing speeches) could lead to a denial of the depigmentation according to Ly [4], and consequently a low attendance of healthcare services. Mahé [11] however, reported that some complications such as acne, stretch marks were considered as evidence of the effectiveness of the products. Lastly, illegal medicine was also practiced. In fact, when women present some dyschromic complications, they return to the store where they got the first product(s) to get other product(s) for the treatment of the complication(s) under the recommendation of the retailer. The brown was the DP users' favorite skin color (68.71\%) far before the bright color (16.67\%). This result is similar to the finding Traoré [1] who found the desire of sunbathing (24.2\%) was the most frequent motivation compare to the need to get a bright skin (7.2\%). It is also closed to the one of Ly et al. [13] who found that the brown skin color was the universal skin color of women from Dakar. It is important to mention that the words "bronzed", "brown", "chocolate" and "white coffee or coffee with milk" were used indifferently by the women during our investigation and were used as an intermediate skin color between the black and the bright color ("not too black, not too bright, shining"). We can see it as euphemisms for not admitting her willingness to change her skin color, for "rejecting" the practice or avoiding negative judgment from investigators. The need may be to enhance the skin color but not to change it. Anyway, the need of DP use is real, and we should take it in account in our appreciation of the phenomenon of artificial depigmentation, as well as in the strategies that will be implemented for its control.

\section{Conclusion}

To sum up, we can attest that the artificial depigmentation is in great progress in Bobo-Dioulasso ( 2 out of 3 women) compare to half, thirteen years ago. The majority of the users were under 30 years old, literate, housewives and married. The hydroquinone was markedly the most frequent depigmentation substance while there was an apparent lack of corticosteroids and mercuries replaced by the new depigmenting agent such as EDTA and kojic acid. Cosmetic shops were the preferred place of supply for users and the cost of the use of DP estimated at about 1700 FCFA per month was relatively modest. The complications were frequent in users and were dominated by dyschromia; but there were only few demands for dermatological care. The ideal skin color desired by users was the brown $(68.71 \%)$ that they tried to get using all means. Our study was unable neither to reveal the exact composition of the DP nor to identify possible general complications associated to their use. Further investigations will be necessary to establish precisely the composition of these products as well as their causality in the occurrence of general complications. The regulation of cosmetic products and the biochemical screening of products imported in Burkina Faso as well as a support to women seem to be the best approaches against this phenomenon 
which has markedly grown. Research in cosmetology should make it possible to provide women with safe products that respect their deep needs.

\section{References}

[1] Traoré, A., Kadéba, J.-C., Niamba, P., Barro, F. and Ouédraogo, L. (2005) Use of Cutaneous Depigmenting Products by Women in Two Towns in Burkina Faso : Epidemiologic Data, Motivations, Products and Side Effects. International Journal of Dermatology, 5, 30-32. https://doi.org/10.1111/j.1365-4632.2005.02807.x

[2] Agence Française de Sécurité Sanitaire des Produits de Santé (2011) Evaluation des risques liés à la dépigmentation volontaire. Paris. 18 .

[3] Berthé, A. (1999) Corps réel-corps idéal. Une analyse sociologique des motivations pour la dépigmentation cutanée: le cas des femmes de la ville de Bobo-Dioulasso. Mémoire de maîtrise en sociologie. Université de Ouagadougou, Ouagadougou, 97.

[4] Ly, F. (2006) Complications dermatologiques de la dépigmentation artificielle en Afrique. Ann Dermatol Venereol, 133, 899-906. https://doi.org/10.1016/S0151-9638(06)71068-7

[5] Djabaku, A. (1998) Contribution à l'étude de la pratique de dépigmentation par les femmes de Ouagadougou (BF). Enquête sur les modes d'utilisation des produits et leurs risques induits. Thèse de doctorat d'Etat en pharmacie, Université de Ouagadougou, Ouagadougou, 48.

[6] Institut National de la Statistique et de la Démographie (BF) (2013) Annuaire Statistique 2012. Ouagadougou, Edition 2013.

[7] Ancelle, T. (2011) Statistique, épidémiologie. 3e édition, Collection Sciences Fondamentales, Paris, 80-81.

[8] Conseil Supérieur de la Communication (Burkina Faso) (2006) Code de la publicité. Articles 40 et 41 .

[9] Wone, I., Tall Dia, A., Diallo, F., Badiane, M., Toure, K. and Diallo, I. (2000) Prévalence de l'utilisation de produits cosmétiques dépigmentants dans deux quartiers de Dakar (Sénégal). Dakar Médical, 45, 154-157.

[10] Pitché, P., Afanou, A., Amanga, Y. and Tchangaï-Walla, K. (1998) Les pratiques cosmétiques dépigmentantes des femmes à Lomé (Togo). Médecine d'Afrique Noire, 45, 709-713.

[11] Mahé, A., Blanc, L., Halna, J., Kéta, S., Sanogo, T. and Bobin, P. (1993) Enquête épidémiologique sur l'utilisation cosmétique de produits par les femmes de Bamako (Mali). Annales de dermatologie et de vénéréologie, 119, 870-873.

[12] Del Giudice, P., Raynaud, E. and Mahé, A. (2003) L'utilisation cosmétique de produits dépigmentants en Afrique. Dermatologie Tropicale, 96, 389-393.

[13] Ly, F., Vasseur-Malié, P., Agne, A. and Verschoore, M. (2007) La dépigmentation artificielle de la peau noire, essai d'analyse anthropologique et psychosociale en

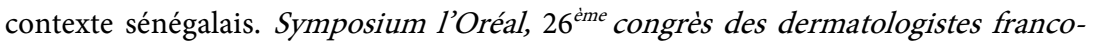
phones, du 13 au 17 Février 2006, Ouagadougou, 37. 
Submit or recommend next manuscript to SCIRP and we will provide best service for you:

Accepting pre-submission inquiries through Email, Facebook, LinkedIn, Twitter, etc. A wide selection of journals (inclusive of 9 subjects, more than 200 journals)

Providing 24-hour high-quality service

User-friendly online submission system

Fair and swift peer-review system

Efficient typesetting and proofreading procedure

Display of the result of downloads and visits, as well as the number of cited articles Maximum dissemination of your research work

Submit your manuscript at: http://papersubmission.scirp.org/

Or contact jcdsa@scirp.org 